\title{
High-brightness anterograde transneuronal HSV1 H129 tracer modified using a Trojan horse-like strategy
} Peng Su ${ }^{1,2+}$, Min Ying
Fuqiang $\mathrm{Xu}^{1,2,3+}{ }^{1,2,5,6^{*}}$, Zengpeng $\mathrm{Han}^{2,3}$, Jinjin $\mathrm{Xia}^{2}$, Sen $\mathrm{Jin}^{2,4}$, Yingli $\mathrm{Li}^{2}$, Huadong Wang ${ }^{2,3,5^{*}}$ (D) and

\begin{abstract}
Neurotropic viral transsynaptic tracing is an increasingly powerful technique for dissecting the structure and function of neural circuits. Herpes simplex virus type 1 strain $\mathrm{H} 129$ has been widely used as an anterograde tracer. However, HSV tracers still have several shortcomings, including high toxicity, low sensitivity and non-specific retrograde labeling. Here, we aimed to construct high-brightness HSV anterograde tracers by increasing the expression of exogenous genes carried by H129 viruses. Using a Trojan horse-like strategy, a HSV/AAV (adenoassociated virus) chimaera termed $\mathrm{H} 8$ was generated to enhance the expression of a fluorescent marker. In vitro and in vivo assays showed that the exogenous gene was efficiently replicated and amplified by the synergism of the HSV vector and introduced AAV replication system. H8 reporting fluorescence was brighter than that of currently available H129 tracers, and H8 could be used for fast and effective anterograde tracing without additional immunostaining. These results indicated that foreign gene expression in HSV tracers could be enhanced by integrating HSV with AAV replication system. This approach may be useful as a general enhanced expression strategy for HSV-based tracing tools or gene delivery vectors.
\end{abstract}

Keywords: Neural circuit tracing, Anterograde tracer, Herpes simplex virus, H129, Adeno-associated virus, Trojan horse-like strategy, High-brightness

\section{Introduction}

Transneuronal tracing of neural circuits using neurotropic viral tools is increasingly being recognized as a powerful approach for defining the synaptic organization of neural networks. Neurotropic viruses have the innate ability to invade neurons and produce infectious progeny that spread along synaptically connected neuronal networks [1-3]. Mapping neural circuits requires both anterograde and retrograde tracers [4]. To date, rabies virus and pseudorabies virus (PRV) strains have been

\footnotetext{
* Correspondence: hdwang@wipm.ac.cn; fuqiang.xu@wipm.ac.cn

${ }^{\dagger}$ Peng Su and Min Ying contributed equally to this work.

${ }^{2}$ Center for Brain Science, State Key Laboratory of Magnetic Resonance and Atomic and Molecular Physics, Key Laboratory of Magnetic Resonance in Biological Systems, Wuhan Center for Magnetic Resonance, Wuhan Institute of Physics and Mathematics, Innovation Academy for Precision Measurement Science and Technology, Chinese Academy of Sciences, Wuhan 430071, China

${ }^{1}$ Wuhan National Laboratory for Optoelectronics, Huazhong University of Science and Technology, Wuhan 430074, China

Full list of author information is available at the end of the article
}

modified for use as retrograde tracers [5-8]. Meanwhile, vesicular stomatitis virus (VSV) and herpes simplex virus type 1 (HSV-1) strain H129, originally isolated from the brain of a patient suffering from acute HSV encephalitis [9], have been reported to spread selectively in the anterograde direction and are widely used as anterograde tracers [10-12]. However, HSV H129 tracers still have several drawbacks, such as high toxicity, low sensitivity, and non-specific labeling. With current transmultisynaptic H129 tracer systems, sampling takes place 3 days after intracranial injection because experimental animals die within $3-5$ days of infection $[13,14]$. Because the fluorescent protein gene carried by $\mathrm{H} 129$ tracers is not highly expressed in 3 days, it is usually necessary to amplify the fluorescent signal by immunohistochemistry to visualize and dissect the structure of the output neural networks [15-17]. For instance, immunostaining for GFP protein provides sensitive detection and high contrast for image analysis. Therefore, a H129 
tracer with increased brightness would be more convenient for anterograde transsynaptic tracing. Furthermore, decreasing the sampling time could increase the likelihood that labeled brain regions are directly related to the injection site. Thus, enhancing the expression of exogenous genes is one of the core objectives for improving HSV1 H129-based viral tracers.

Here, we aimed to increase the expression of exogenous genes carried by $\mathrm{H} 129$ tracers by constructing a HSV/adeno-associated virus (AAV) chimaera virus. AAVs are naturally replication-defective human parvoviruses. With their small and relatively simple genomes, AAVs have become preferred viral vectors for gene delivery, primarily because they exhibit little or no toxicity and do not cause inflammation [18-20]. AAVs require the presence of a helper virus (adenovirus or HSV) to trigger replication and the generation of progeny viruses $[21,22]$. As such, one of the most important large-scale production methods for the generation of recombinant AAV (rAAV) vectors is employing the HSV platform $[23,24]$. Furthermore, AAVs can sometimes assist in enhancing the expression of transgenes in plasmid vectors. For example, plasmid-based HSV pseudoviral amplicon vectors show great promise in gene therapy and have been studied for several decades [25, 26]. Studies have shown that long-term transgene expression can be achieved when the AAV rep gene is added along with the transgene of interest into the HSV-1 amplicon plasmid, with the transgene flanked with AAV inverted terminal repeat elements (ITRs) [27-29].

In the present study, we designed and applied a Trojan horse-like strategy whereby an AAV replication system was directly introduced into the HSV viral genome to enhance the replication and expression of an enhanced green fluorescent protein gene (egfp), which is different from the plasmid-based pseudoviral hybrid amplicon system (Fig. 1a). We constructed H1 (routine tracer) and $\mathrm{H} 8$ chimeric viruses (novel high-brightness tracer) containing identical egfp expression cassettes except that $\mathrm{H} 8$ also contained an AAV replication system to control the replication and expression of the egfp gene. In vitro and in vivo assays showed high levels of exogenous gene expression by the $\mathrm{H} 8$ virus, suggesting that the chimeric virus could be more convenient and flexible for anterograde transneuronal tracing.

\section{Materials and methods}

\section{Animals}

All experimental and surgical procedures were conducted in accordance with the guidelines of the Animal Care and Use Committees at the Wuhan Institute of Physics and Mathematics, Chinese Academy of Sciences. Adult male C57BL/6 mice were purchased from Hunan SJA Laboratory Animal Company. All animals were housed in a dedicated housing room with a $12 / 12 \mathrm{~h}$ light/dark cycle, and food and water were available ad libitum. All the experiments with viruses were performed in bio-safety level 2 (BSL-2) laboratory and animal facilities.

\section{Cells and viruses}

The wildtype HSV-1 H129 strain was generously provided by Professor Lynn Enquist (Princeton University, Princeton, NJ). Viral stocks were grown on Vero cells maintained in Dulbecco's minimum essential media (DMEM) with $10 \%$ fetal bovine serum (FBS). Standard plaque assays were performed by serially diluting virus in DMEM supplemented with 2\% FBS (2\% DMEM) and overlaying infected cells with medium containing $2 \%$ FBS, antibiotics, and 1\% agarose. Plaques were identified using neutral red staining and/or fluorescence microscopy where appropriate. Aliquots of viral stocks were stored frozen at $-80{ }^{\circ} \mathrm{C}$.

\section{Construction of $\mathrm{H} 129$ recombinant $\mathrm{H} 1$ and $\mathrm{H} 8$ viruses}

To construct H1, the EGFP expression cassette was inserted into the intergenic region between the UL37 and UL38 genes. The UL37 and UL38 homology arms and reporter gene were cloned into the vector pcDNA3.1+ to generate the targeting plasmid. Briefly, UL37-UHA (upstream homology arm) and UL38-DHA (downstream homology arm) were generated by PCR using H129 genome DNA as the templates. Subsequently, the homology arms were ligated into the pcDNA3.1+ vector and a new MCS site (HpaI-AgeIBamHI-Sbfl) was inserted between the two arms. The EGFP expression cassette containing hUbC promoter, EGFP gene, WPRE and $b G H$ ploy (A) signal was inserted between $U L 37$ and UL38 homology arms to create $p H$ 129-hUbC-EGFP-WPRE.

The strategy adopted to produce $\mathrm{H} 8$ virus was to introduce AAV replication system into HSV genome to construct HSV/AAV chimeric virus. AAV replicase expression cassette (CMV-Rep-PA) and ITR as flanking elements of fluorescent gene expression cassette were also inserted into the intergenic region between the UL37 and UL38 genes (Fig. 1b). In brief, the codon-modified Rep gene of AAV serotype 2 expression cassette (CMV-Rep$P A$ ) was digested with SbfI and AgeI, and then introduced into the same enzymes digested $3.1+37$ arm-38 arm vector to create $p H$ 129-CMV-Rep plasmid. The EGFP expression cassette containing $h U b C$ promoter, EGFP gene, WPRE and $b G H$ ploy (A) signal was inserted between the two ITRs of the cloning vector $p F D$-(ITR-GFP). Then the whole ITR flanked EGFP expression cassette was digested with SbfI and ligated into SbfI-digested $p H$ 129-CMV-Rep vector to create $p H 129-C M V$-Rep/ITR-hUbC-EGFPWPRE-ITR targeting vector. Successful construction and function of the targeting plasmid was confirmed by 

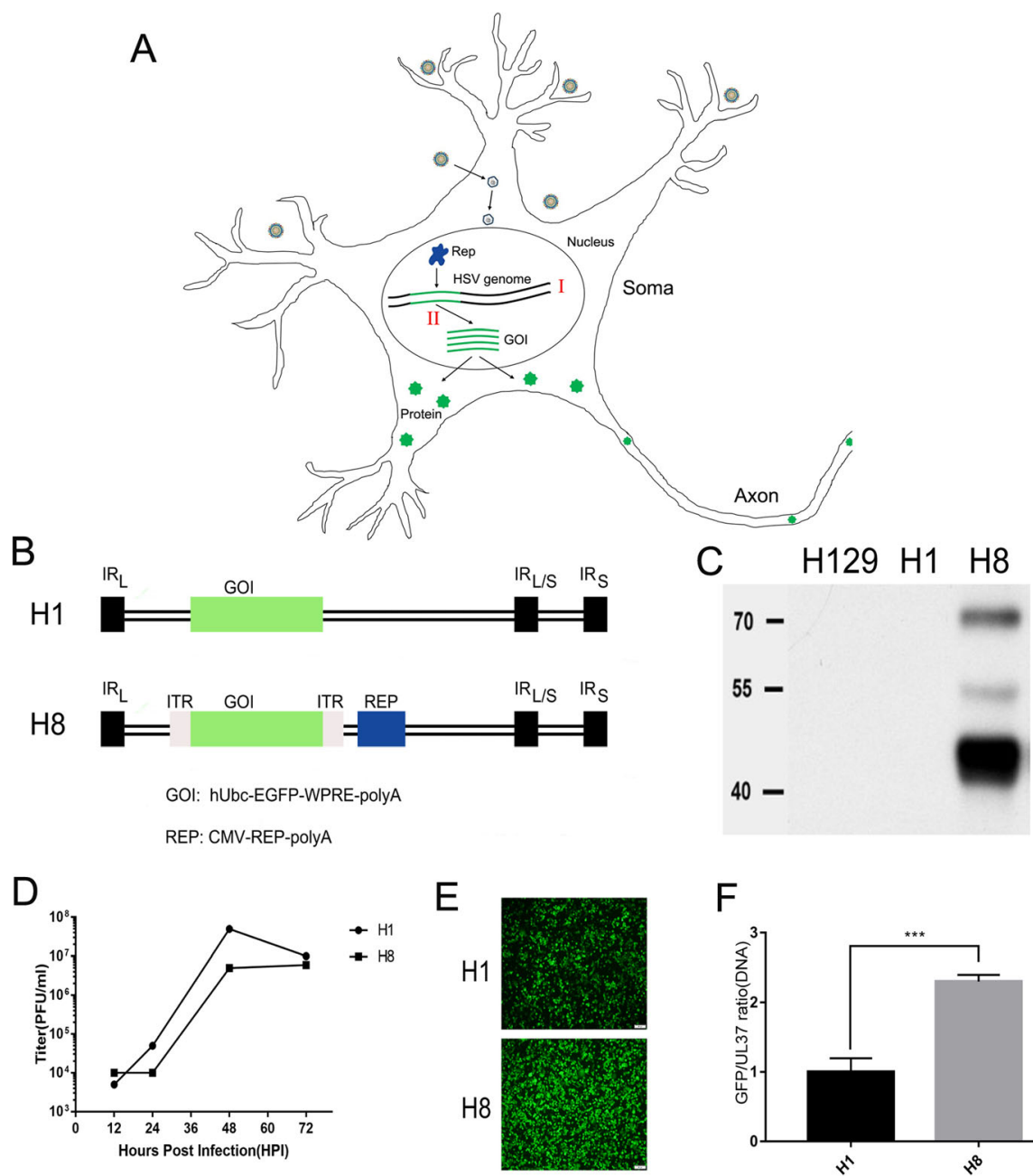

F

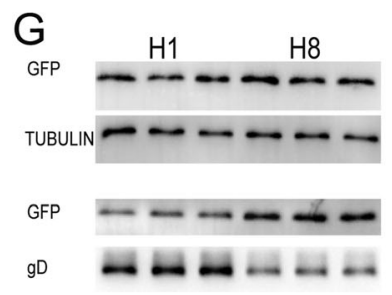

$\mathrm{H}$
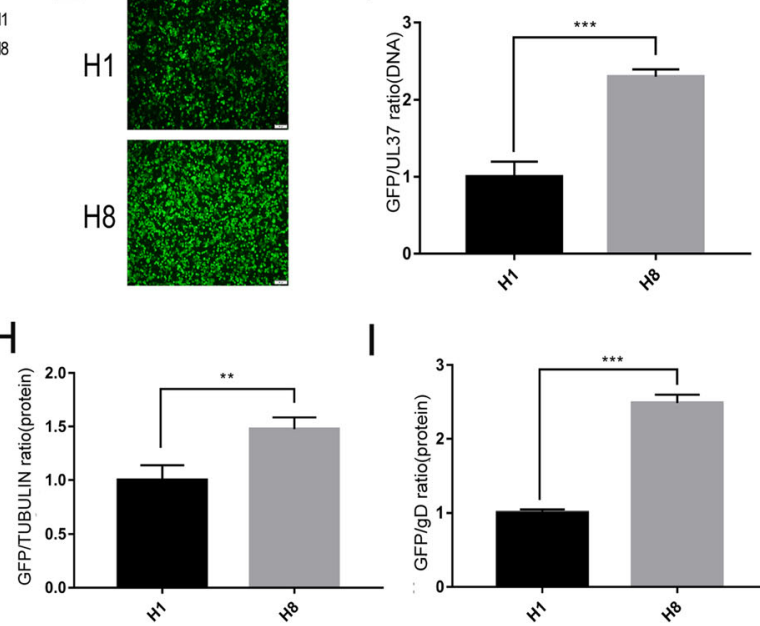

I

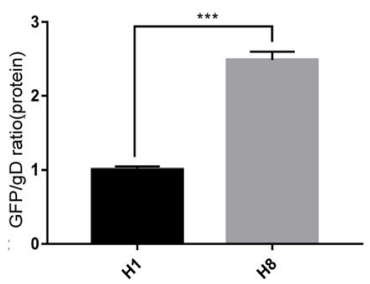

Fig. 1 Construction and validation of $\mathrm{H} 1$ and $\mathrm{H} 8$ viruses in vitro. a The Trojan horse-like strategy of GOI amplification by HSV/AAV chimaera. AAV replicase expression cassette and ITR flanked GOI (gene of interest) cassette were inserted into H129 genome to construct the chimaera virus. The genome of the HSV chimaera enters the nucleus following infection of cells. With the assistance of HSV, the Rep replicase specifically recognizes GOI flanked by ITRs and replicates it, resulting in amplification of the copy numbers of the GOI. b Schematic of H1 and H8 genome. IRL and IRS indicate long and short inverted repeats, respectively. c Western blot validation of rep protein expression. H129, H1 and H8 infected BHK cells were detected using the anti-replicase antibody. $\mathbf{d}$ Single-step growth curves for $\mathrm{H} 1$ and $\mathrm{H} 8$ (each point represents the mean of triplicate assays). e Fluorescent protein expression level of $\mathrm{H} 1$ and $\mathrm{H} 8$ infected BHK cells at $24 \mathrm{~h}$ post infection, $\mathrm{MOI}=5$. Scale bar, $100 \mu \mathrm{m}$. $\mathbf{f} \mathrm{H} 8$ showed significant higher DNA level of egfp than H1. $\mathbf{g}, \mathbf{h}, \mathbf{i}$ H8 showed significant higher protein level of GFP than H1. The genomes and proteins of H1 and H8 infected BHK cells were extracted 48 hpi

restriction enzyme digestion, sequencing and transfection into $293 \mathrm{~T}$ cells (data not shown).

To generate $\mathrm{H} 1$ (rH129-hUbC-EGFP-WPRE) and H8 (rH129-CMV-Rep/ITR-hUbC-EGFP-WPRE-ITR) recombinant viruses, the corresponding expression cassettes were inserted the H129 genome via homologous recombination. The resulting plasmids $p H 129-h U b C-E G F P$ WPRE and pH 129-CMV-Rep/ITR-hUbC-EGFP-WPRE$I T R$ were purified by Omega plasmid mini kit and separately co-transfected with H129 genomic DNA into $293 \mathrm{~T}$ 
cells in six-well plates, using Lipofectamine 2000 (Invitrogen) according to the manufacturer's instructions. After the majority of cells showed cytopathic effect, the medium was removed and the cells were harvested in PBS. After three-rounds of freeze-thaw-vortex, the cell lysate was used to infect Vero cells plated in six-well plates. After one hour of infection, viruses were removed and DMEM with $2 \%$ FBS, antibiotics, and $1 \%$ agarose were overlaid on the cells. After 2 or 3 days, wellseparated EGFP-expressing plaques were picked and subjected to at least five more rounds of plaquepurification to remove wild type H129 virus.

The novel purified $\mathrm{H} 1$ and $\mathrm{H} 8$ viruses were massproduced by infecting Vero cells grown in T75 tissue culture flasks. After infected cells showed a prominent cytopathic effect ( $\sim 2$ days), medium containing the viruses was collected, centrifuged to remove cell debris $(7000 \mathrm{~g}$ for $10 \mathrm{~min}$ ), the supernatant passed through a $0.22 \mu \mathrm{m}$ filter, and finally centrifuged at 50,000 g/3 h using Beckman Avanti J-26SXP Ultracentrifuge. The virus pellet was resuspended overnight at $4{ }^{\circ} \mathrm{C}$ in a small amount of cold PBS. Dissolved viruses were aliquoted into $3 \mu \mathrm{l}$ and stored at $-80^{\circ} \mathrm{C}$. The titer of viral stocks was determined using standard plaque assay on Vero cells and titers were expressed as plaque-forming units (PFU) per milliliter. A fresh aliquot of stock virus was thawed and used for each experiment. The titers of virus stocks used in these studies were $\sim 3 \times 10^{9} \mathrm{PFU} / \mathrm{ml}$ for $\mathrm{H} 1$ or $\mathrm{H} 8$ virus.

\section{Viral growth kinetics analysis}

BHK-21 cells $\left(5 \times 10^{5}\right)$ were plated into six-well plates, and infected with either $\mathrm{H} 1$ or $\mathrm{H} 8$ at a multiplicity of 10 $\mathrm{PFU} /$ cell. After $1 \mathrm{~h}$ of adsorption, the viral inocula were removed (time point 0 ), cells were washed 3 times with PBS to remove unabsorbed virus and DMEM medium (containing 2\% FBS) was added. Supernatants were collected at different time points as indicated (12, 24, 48 and $72 \mathrm{~h}$ post infection (HPI)) and virus titers were determined by standard plaque assays.

\section{Q-PCR and Western blot \\ Q-PCR assay}

For in vitro test, the BHK cells were infected with $\mathrm{H} 1$ or $\mathrm{H} 8$ virus at $\mathrm{MOI}=0.1$ in a six-well plate, respectively. After $48 \mathrm{~h}$, the supernatant was discarded and the cells were rinsed with PBS before scraped down for DNA or protein extraction. For in vivo detection, $200 \mathrm{nl} \mathrm{H} 1$ or H8 virus was injected into midbrain VTA region of 4 adult C57BL/6 mice, respectively. Three days after injection, mice brains were collected and ground evenly in liquid nitrogen with $1 \mathrm{ml}$ lysis buffer. Then, $100 \mu \mathrm{l}$ lysate of each brain was used to extract genome or protein. The genome was extracted using the Tissue DNA Kit (D3396, OMEGA). For protein extraction, cells or brain tissues were resuspended in cell lysis buffer (Beyotime Biotechnology), stand at room temperature for $10 \mathrm{mi}$ nutes, centrifuged at $10000 \mathrm{~g}$ for 10 minutes and then remain the supernatant.

Gene copy number were determined by qPCR assay with the iQ SYBR Green Supermix kit (Bio-Rad). A standard curve was obtained using 10-fold serial dilutions of plasmid pH 129-CMV-Rep/ITR-hUbC-EGFPWPRE-ITR. The quantitative primers for UL37 and eGFP were $Q-U L 37-F$ (ACAGCGTAGACCAACGACGAGA) and Q-UL37-R (AACGGGATGCCGGGACTTA), QeGFP-F (AAGCAGAAGAACGGCATCA) and Q-eGFP$R$ (GGCGGTCACGAACTCCA), respectively.

\section{Western blot}

Samples were denatured in $5 \times$ loading buffer at $99^{\circ} \mathrm{C}$ for $8 \mathrm{~min}$, and separated by using 10\% SDS-PAGE electrophoresis and then transferred onto polyvinylidene fluoride (PVDF) membranes. GFP proteins were detected using a rabbit anti-GFP antibody (ab290, Abcam) at a 1: 2000 dilution. HSV gD proteins were detected using a mouse monoclonal antibody (ab6507, Abcam) at a 1 : 5000 dilution. A monoclonal antibody against $\beta$-tubulin (Proteintech) was used at a 1:8000 dilution. Secondary detection antibodies were used at a 1:5000 dilution. The images were collected and analyzed by gel-imaging (BioRad, ChemiDocTM MP).

\section{Stereotactic surgery}

All procedures on animals were performed in Biosafety level 2 (BSL-2) animal facilities as before [30]. Animals were anesthetized with pentobarbital sodium by intraperitoneal injection $(80 \mathrm{mg} / \mathrm{kg}$, i.p.), and placed in a stereotaxic apparatus (Item: 68030, RWD, Shenzhen, China). During surgery and virus injection, all animals were kept anesthetized with isoflurane (1-1.5\%). The skull above the targeted areas was thinned with a dental drill and removed carefully. Injections were conducted with a syringe pump (Item: 53311, Quintessential stereotaxic injector, Stoelting, United States) connected to a glass micropipette with a tip diameter of $10-15 \mathrm{~mm}$. The glass micropipette was held for an extra $10 \mathrm{~min}$ after the completion of the injection and then slowly retreated. After the surgery, the incisions were stitched and lincomycin hydrochloride and lidocaine hydrochloride gel was applied to prevent inflammation and alleviate pain for the animals.

$6 \times 10^{5}$ PFU H1 or $\mathrm{H} 8$ was injected into the adult male C57BL/6 mice $(n=3)$ with the following coordinates: VTA (AP, $-3.20 \mathrm{~mm}$; ML, $-0.40 \mathrm{~mm}$; and DV, -4.30 $\mathrm{mm}$ ), V1 (AP, $-2.80 \mathrm{~mm}$; ML, $-2.40 \mathrm{~mm}$; and DV, $0.90 \mathrm{~mm}$ ), NAc (AP, $+1.0 \mathrm{~mm}$; $\mathrm{ML},-1.1 \mathrm{~mm}$; and DV, $-4.50 \mathrm{~mm}$ ). To determine whether $\mathrm{H} 8$ might allow neural circuit labeling in a shorter time period, $\mathrm{H} 8$ was injected into the accumbens nucleus (NAc) of adult 
C57BL/6 mice and collected samples at 24,36 , and $48 \mathrm{~h}$ post-injection.

\section{Slice preparation and confocal imaging}

The mice were anesthetized with pentobarbital sodium (100 mg/kg body weight, i.p.), and perfused transcardially with PBS ( $5 \mathrm{~min}$ ), followed by ice-cold $4 \%$ paraformaldehyde (PFA, 158127 MSDS, sigma) dissolved in PBS (5 min). The brain tissues were carefully removed and post-fixed in PBS containing $4 \%$ PFA at $4{ }^{\circ} \mathrm{C}$ overnight, and then equilibrated in PBS containing $25 \%$ sucrose at $4{ }^{\circ} \mathrm{C}$ for $72 \mathrm{~h}$. The $40 \mu \mathrm{m}$ thick coronal slices of the whole brain were obtained using the cryostat microtome and stored at $-20^{\circ} \mathrm{C}$.

For all samples, every sixth section of the brain slices were selected, stained with DAPI, washed with PBS, mounted with 70\% glycerol (in PBS) and sealed with nail polish. All of the images were captured with the Olympus VS120 virtual microscopy slide scanning system (Olympus, Shanghai, China).

\section{Data analysis}

SPSS (version 13.0) and Origin 9.0 were used for data analysis (student's $t$-tests) and statistical graphs, respectively. All data were presented as means \pm SEM. Statistical significance was set as ${ }^{*} P<0.05,{ }^{* * *} P<0.01$ and ${ }^{* * * *} P<0.001$.

\section{Results}

\section{Construction and characterization of the $\mathrm{H} 8$ chimeric virus in vitro}

The H8 chimeric virus was generated by the introduction of the AAV replication system (replicase and ITR elements) into the HSV1 strain H129 genome to enhance the expression of an exogenous gene of interest (GOI), which, in this case, was egfp. Figure 1a showed the construction strategy used in this study. While the $\mathrm{H} 1$ and $\mathrm{H} 8$ viruses contained the same egfp expression cassettes, H8 also contained the AAV replication system to enhance the replication of the egfp gene (Fig. 1b). Western blotting experiments showed that the $\mathrm{H} 8$ virus effectively expressed the AAV Rep protein, while no Rep expression was detected in H1- or wild type H129-infected cells (Fig. 1c). Analysis of viral growth kinetics showed that $\mathrm{H} 8$ replication was only slightly slower than that of $\mathrm{H} 1$, which can be observed in the single-step replication curve (Fig. 1d).

As expected, the green fluorescence of $\mathrm{H} 8$ chimeric virus-infected cells was significantly brighter than that of H1-infected cells (Fig. 1e). qPCR analysis was conducted to quantify the egfp expression cassette copy number, while the amplified UL37 gene fragment was selected as an indicator of the HSV genome copy number. One HSV genome has only 1 copy of the UL37 gene, which was consistent with the qPCR result of egfp/UL37 ratio of H1 (Table 1). The egfp/UL37 ratio from $\mathrm{H} 1$ was defined as 1 . The results showed that the egfp/UL37 ratio for the $\mathrm{H} 8$ virus was significantly higher than that of the $\mathrm{H} 1$ virus (Table 1 and Fig. 1f), indicating that there was a greater number of copies of egfp in the H8-infected cells than in the H1-infected cells. Thus, these findings confirmed that the Rep protein expressed by the HSV/ AAV chimeric vector could effectively replicate the ITRflanked exogenous gene. The egfp/UL37 ratio for $\mathrm{H} 8$ was $\sim 2.30$ ( \pm 0.06 ), indicating that its egfp copy number was $>2$-fold higher than that of the H129 genome.

Western blotting was then performed to quantify GFP expression by both $\mathrm{H} 1$ and $\mathrm{H} 8$. To exclude the effect of amplification speed differences, both cellular tubulin and HSV glycoprotein D were selected as internal references (Fig. 1g). For quantification, the EGFP/IR (internal reference) ratio from the $\mathrm{H} 1$ virus was defined as 1 . When tubulin was used as the internal reference, the EGFP/IR ratio for strain $\mathrm{H} 8$ was $1.48( \pm 0.06)$ (Additional file 1: Table S1), whereas a ratio of $2.49( \pm 0.07)$ (Additional file 1: Table S2) was recorded when glycoprotein D was used as the internal reference (Fig. 1h, i). Taken together, these results showed that EGFP copy number and expression was significantly higher in H8-infected cells than in H1-infected cells.

\section{In vivo validation of $\mathrm{GO}$ expression enhancement of the H8 chimeric virus}

To test whether $\mathrm{H} 8$ produced a strong labeling signal in vivo, we separately injected $\mathrm{H} 1$ and $\mathrm{H} 8$ into the VTA of adult C57BL/ 6 mice. At 3 days post-injection, whole brains were harvested from infected mice and used for qPCR and Western blotting analyses to determine egfp gene and protein levels (Fig. 2a).

Not unexpectedly, in vivo experiments showed higher levels of egfp in H8-infected brains compared with H1infected brains (Fig. 2b). At the gene level, the egfp/UL37 ratio for $\mathrm{H} 8$ was $\sim 1.71( \pm 0.10)$, indicating that the egfp copy number was 1.7 -fold higher than the HSV genome copy number (Table 2). At the protein level, a correspondingly higher EGFP expression level was observed in H8-infected mice compared with H1-infected mice (Fig. 2c). When tubulin was used as the internal reference, the EGFP/IR ratio for $\mathrm{H} 8$ was $6.71( \pm 1.36)$ (Additional file 1: Table S3), and a ratio of $3.19( \pm 0.35)$ (Additional file 1: Table S4) was determined when using glycoprotein $\mathrm{D}$ as the internal reference (Fig. 2d, e). The results indicated that GOI copy number and protein expression was significantly higher in H8infected mice compared with H1-infected mice.

Comparison of neural circuit tracing efficiency of H8 and $\mathrm{H} 1$ in vivo was conducted. $\mathrm{H} 8$ and $\mathrm{H} 1$ were separately injected into the VTA of C57BL/6 mice. Whole brains were harvested from infected mice 3 days later. Brain slices confirmed that EGFP expression by the H8 virus was obviously higher than that of $\mathrm{H} 1$, with differences even apparent to the naked eye (Additional file 1: 
Table 1 Q-PCR assay was conducted to quantify the egfp expression cassette copy number in $\mathrm{H} 1$ or $\mathrm{H} 8$ infected cells in vitro ${ }^{\mathrm{a}}$

\begin{tabular}{|c|c|c|c|c|c|}
\hline Sample & UL37 quantity & UL37 adjusted quantity & egfp quantity & Adjusted relative ratio & Average ratic \\
\hline $\mathrm{H} 1$ & $21,996,416.00$ & $23,379,909.17$ & $18,561,812.00$ & 0.79 & $1.00 \pm 0.11$ \\
\hline $\mathrm{H} 1$ & $21,587,338.00$ & $22,945,101.68$ & $23,500,664.00$ & 1.02 & \\
\hline $\mathrm{H} 1$ & $20,390,316.00$ & $21,672,791.42$ & $25,614,332.00$ & 1.18 & \\
\hline H8 & $14,824,173.00$ & $15,756,558.63$ & $37,436,844.00$ & 2.38 & $2.30 \pm 0.06^{b}$ \\
\hline H8 & $13,998,001.00$ & $14,878,423.46$ & $34,695,536.00$ & 2.33 & \\
\hline H8 & $14,782,463.00$ & $15,712,225.22$ & $34,447,996.00$ & 2.19 & \\
\hline
\end{tabular}

${ }^{a}$ BHK cells were infected with $\mathrm{H} 1$ or $\mathrm{H} 8$ virus at $\mathrm{MOI}=0.1$ in a six-well plate. After $48 \mathrm{~h}$, the supernatant was discarded and the cells were rinsed with PBS before scraped down for DNA or protein extraction. Gene copy number of GOI were determined by qPCR assay with the iQ SYBR Green Supermix kit (Bio-Rad). Results were expressed as means \pm SEM of each group

${ }^{\mathrm{b}}$ Significant difference $(p<0.001)$, compared with $\mathrm{H} 1$ group

Figure S1A). H8 viruses could efficiently label the neurons with high fluorescent intensity following intracerebral injection. Many neurons of both injection site and various VTA output brain regions were well labeled. The fluorescence intensity of $\mathrm{H} 8$ was sufficient to clearly label and visualize the neuronal cell bodies and nerve fibers (Additional file 1: Figure S1B). These results confirmed that the HSV/AAV chimeric viral tracers worked well in vivo, and $\mathrm{H} 8$ traced output neural circuits more efficiently, and fluorescence labeling was much brighter than that of H1. Meanwhile, it was notable that H8 might exhibit some non-specific retrograde labeling. Our previous research found that $\mathrm{H} 129$ derived tracers were also able to infect neurons of upstream brain regions via direct retrograde uptake/transmission, especially at longer post-inoculation intervals [31]. The labeled hippocampus or dorsal raphe by $\mathrm{H} 8$ might be the direct retrograde labeling regions from the VTA injection site.

\section{In vivo validation of the anterograde transport phenotype of $\mathrm{H} 8$ virus as wildtype $\mathrm{H} 129$}

Recombinant H1 constructed based on wild type H129 was used to be an anterograde tracer, and it has been used to dissect output neural circuits in many cases.

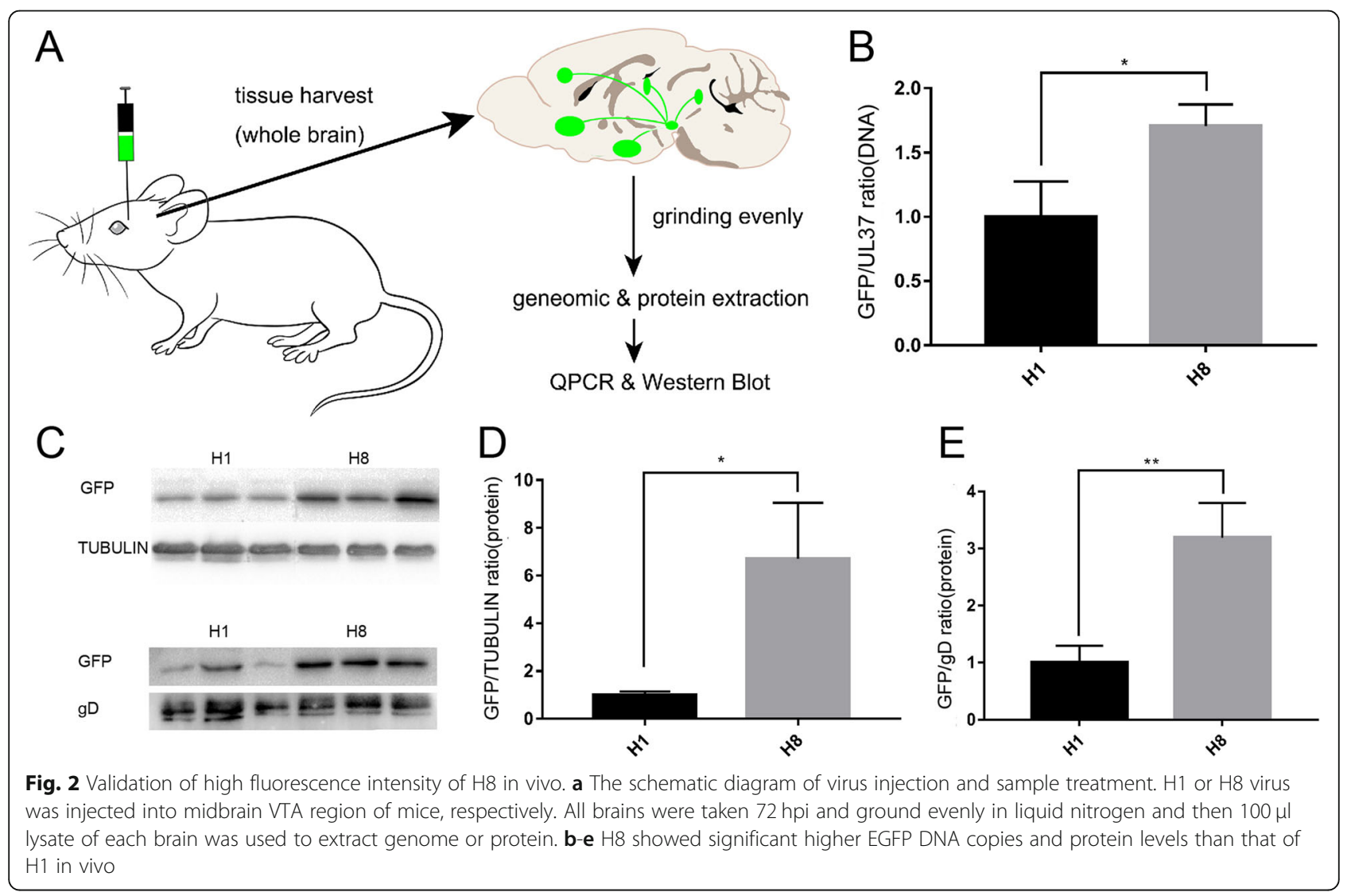


Table 2 In vivo gene copy number of exogenous gene in H1 or H8 infected mice brains were assessed using Q-PCR assay ${ }^{\mathrm{a}}$

\begin{tabular}{|c|c|c|c|c|c|}
\hline Sample & UL37 quantity & UL37 adjusted quantity & egfp quantity & Adjusted relative ratio & Average ratio \\
\hline $\mathrm{H} 1$ & $6,028,302.00$ & $9,995,136.49$ & $7,109,552.50$ & 0.71 & $1.00 \pm 0.16$ \\
\hline $\mathrm{H} 1$ & $16,667,208.00$ & $27,634,816.37$ & $28,367,098.00$ & 1.03 & \\
\hline $\mathrm{H} 1$ & $2,208,835.25$ & $3,662,326.44$ & $4,622,589.50$ & 1.26 & \\
\hline H8 & $5,432,914.50$ & $9,007,963.10$ & $13,658,822.00$ & 1.52 & $1.71 \pm 0.10^{b}$ \\
\hline H8 & $5,167,673.00$ & $8,568,183.37$ & $15,538,736.00$ & 1.81 & \\
\hline H8 & $7,823,168.50$ & $12,971,088.20$ & $23,258,302.00$ & 1.79 & \\
\hline
\end{tabular}

${ }^{a}$ For in vivo detection, $200 \mathrm{nl} \mathrm{H1}$ and $\mathrm{H} 8$ virus was injected into midbrain VTA region of C57BL/6 mice, respectively. Three days after injection, mice brains were collected and ground evenly in liquid nitrogen with $1 \mathrm{ml}$ lysis buffer. Then, $100 \mu$ lysate of each brain was used to extract genome or protein. Gene copy number of GOI were determined by qPCR assay with the iQ SYBR Green Supermix kit (Bio-Rad). Results were expressed as means \pm SEM of each group

b Significant difference $(p<0.05)$, compared with $\mathrm{H} 1$ group

Since H8 was constructed at the same locus of wild type $\mathrm{H} 129$ as $\mathrm{H} 1$, we suspected that $\mathrm{H} 8$ would possess the same transport phenotype as $\mathrm{H} 1$.

To validate this suspicion, V1 (primary visual cortex) injection of $\mathrm{H} 1$ and $\mathrm{H} 8$ experiments was performed. Three days after injection, the mouse brains were collected for imaging. We observed GFP-expressing cell bodies in regions known to be directly projected by V1, including the superior colliculus (SC), ventral lateral geniculate nucleus (LGNv), and caudate putamen (CPU) (Fig. 3). As SC and CPU supposedly should not project back to V1 [32,33], the presence of $\mathrm{GFP}^{+}$cell bodies in these areas may be explained by the anterogradely transneuronal spread of the virus from V1 axons to neurons in their targeted structures. In the brain regions that were reciprocally connected with V1 (e.g., dorsal lateral geniculate nucleus, LGNd), GFP labeling of cell bodies might result from both anterograde and retrograde transport of the virus. These regions were not considered in the current study because of the ambiguity. Due to the observation of the same labeling profiles for $\mathrm{H} 1$ (Fig. 3a) and $\mathrm{H} 8$ (Fig. 3b) in vivo, the results confirmed that $\mathrm{H} 8$ could also be used as an anterograde tracer.

\section{Using $\mathrm{H} 8$ to dissect neural circuits in a shorter timeframe} The observed higher fluorescent protein expression for the $\mathrm{H} 8$ virus might allow neural circuit labeling in a shorter time period. To examine this possibility, we

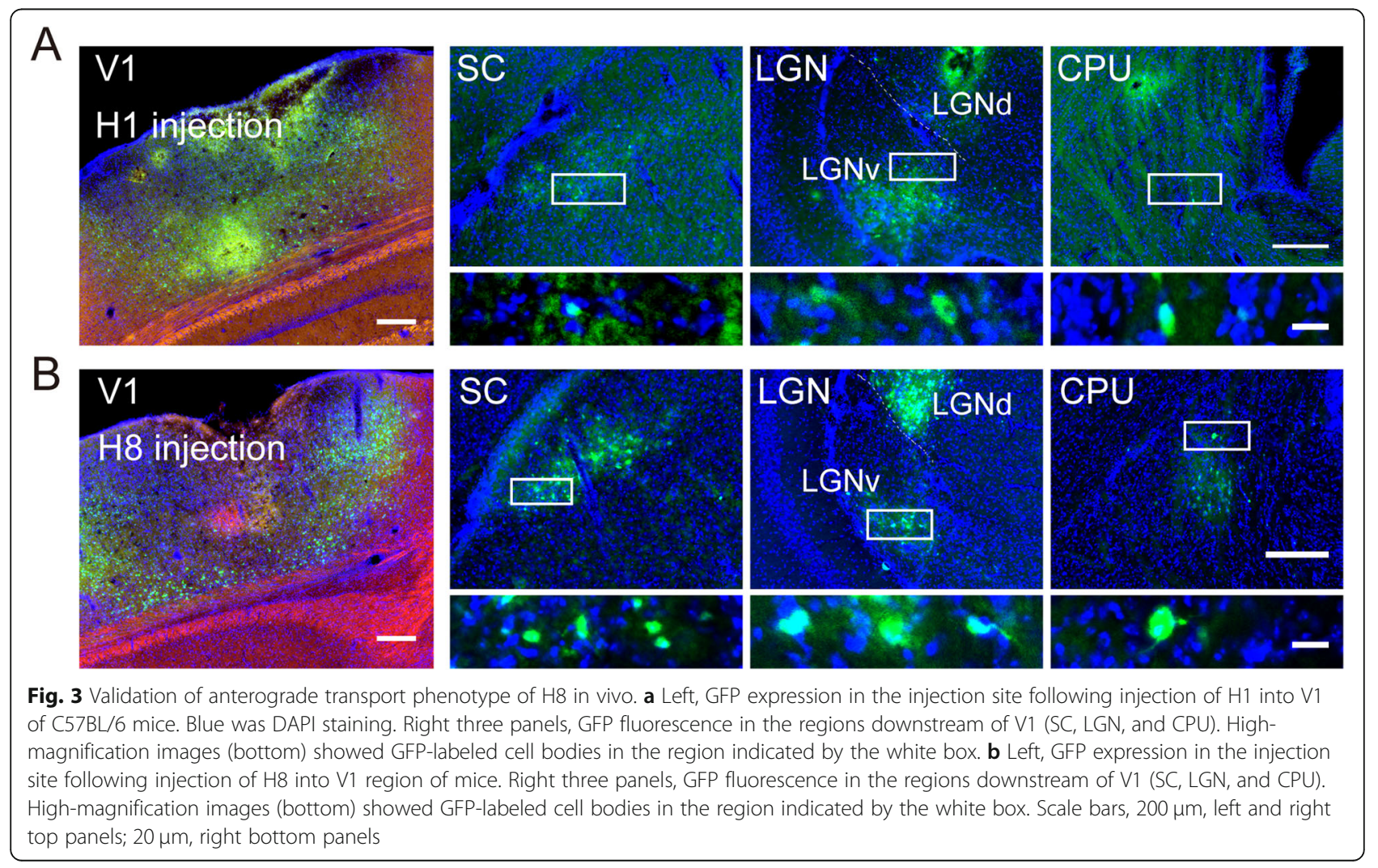


injected $\mathrm{H} 8$ into the nucleus accumbens (NAc) of adult C57BL/6 mice and collected samples at 24, 36, and $48 \mathrm{~h}$ post-injection (Fig. 4 and Fig. 5).

At $24 \mathrm{~h}$ post-injection, fluorescence was only observed at the injection site, indicating no transneuronal spread of the $\mathrm{H} 8$ virus. However, at $36 \mathrm{~h}$ post-injection, fluorescence was observed in many discrete brain areas, including the anterior olfactory nucleus $(\mathrm{AON})$, the orbital cortex (ORB), the agranular insular cortex (AI), the piriform cortex (Pir), the substantia innominata (SI), the paraventricular thalamic nucleus (PVN), the amygdala (AMY), the entorhinal cortex (ENT), the hippocampus (HIP), and the ventral tegmental area (VTA), amongst others. Nuclei labeled at this time point may be directly connected to or receive the strongest outputs from the accumbens nucleus [34]. After a longer infection time (48 $\mathrm{h}$ post-injection), fluorescence was detected across a much wider range of brain regions, including the lateral hypothalamus (LHA), dorsal raphe nuclei (DRN), and most parts of the cerebral cortex (Fig. 4). Thus, these regions might be indirect neural outputs from the injection site (Fig. 6). It was speculated that $\mathrm{H} 8$ injected into the nucleus accumbens might be transmitted anterogradely across multiple synapses to infect and label the cerebral cortex.

As a control, we also examined H1 EGFP expression at $36 \mathrm{~h}$ post-injection. At this time point, all brain regions labeled by $\mathrm{H} 8$ were also traced by $\mathrm{H} 1$, although GFP intensity was much lower than that of H8. However, after immunohistochemical staining using antiGFP antibody, the $\mathrm{H} 1$ virus labeled a greater number of brain regions than H8 (Fig. 5). These findings indicated that $\mathrm{H} 8$ could be used as a more bright and flexible anterograde neural circuit tracer without immunostaining, compared with the currently available HSV tracers.

\section{Discussion}

To fully understand information transfer throughout the nervous system, the connections among neurons need to be defined first. This requires careful definition of the synaptic inputs and outputs of specific neuronal subpopulations in different regions. HSV1 strain H129 is the

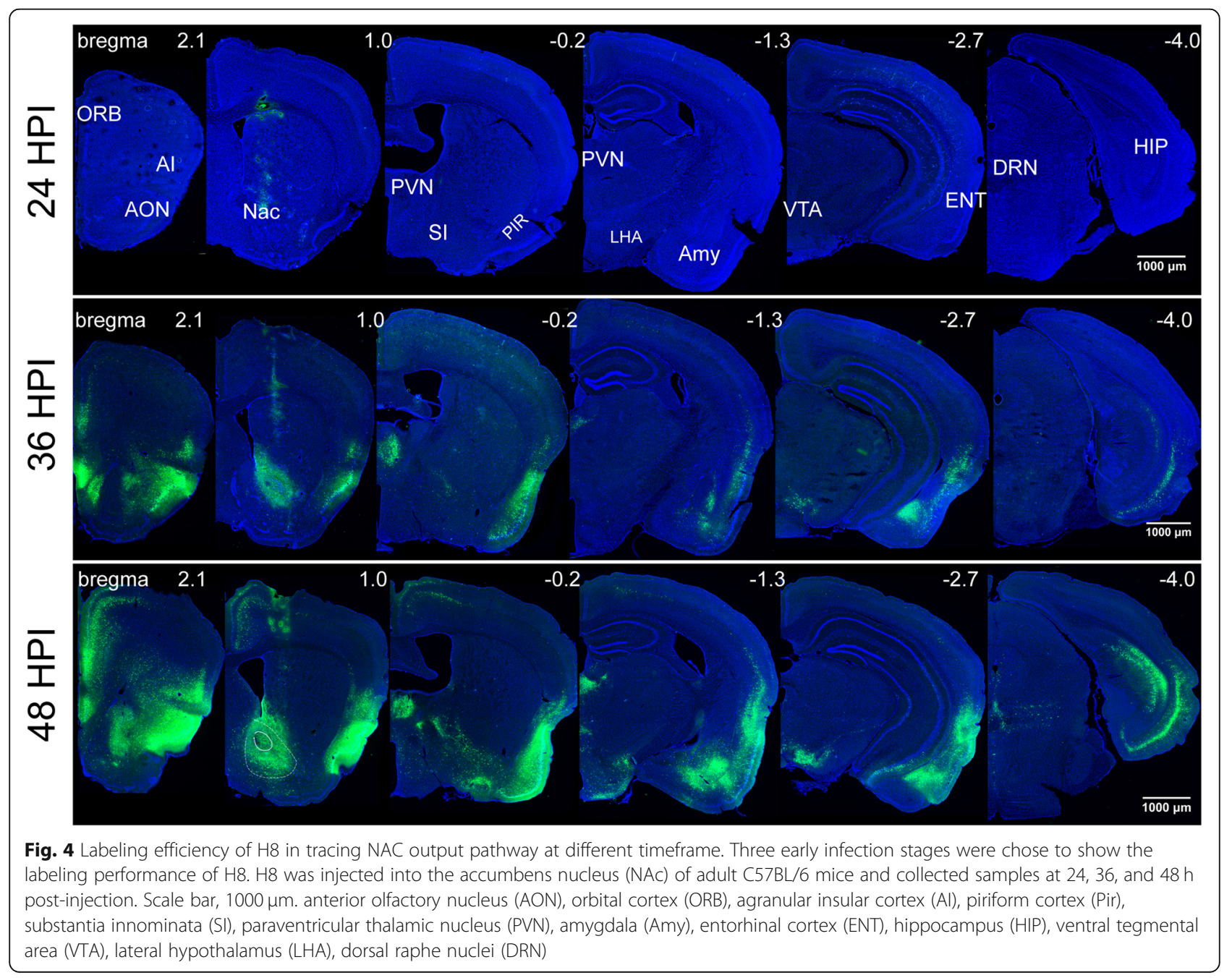




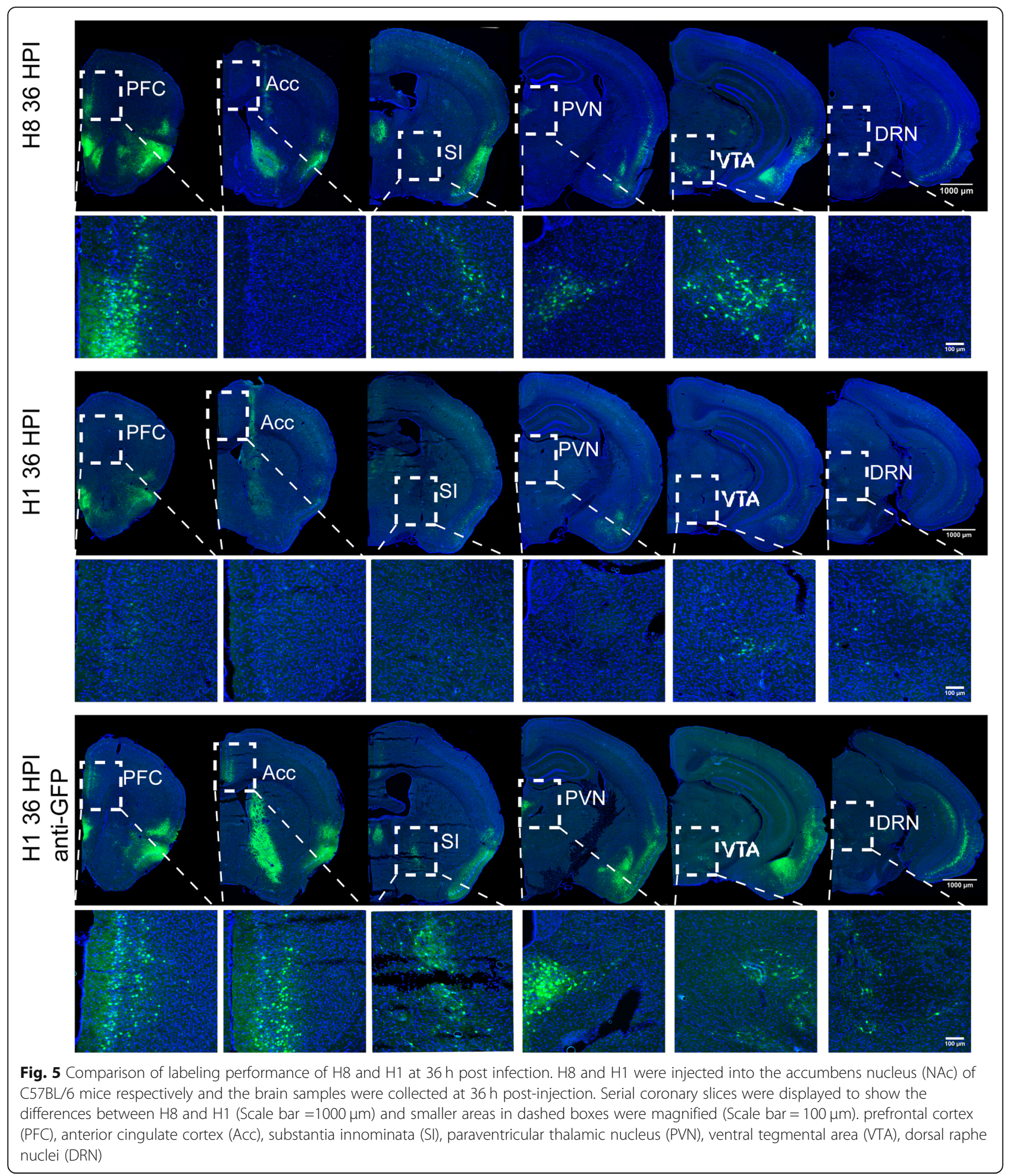

most widely used anterograde transsynaptic tracer and has a relatively high transneuronal spread efficiency. The expression of fluorescent protein by H129 makes it simple to dissect neural circuits using an optical microscope. As such, higher fluorescein expression levels make it easier to detect the viral tracer labeling. However, the majority of currently available H129 viral tracers are limited by their low gene expression levels. Therefore, it is usually necessary to amplify the fluorescent signal by immunostaining using fluorescein-specific 

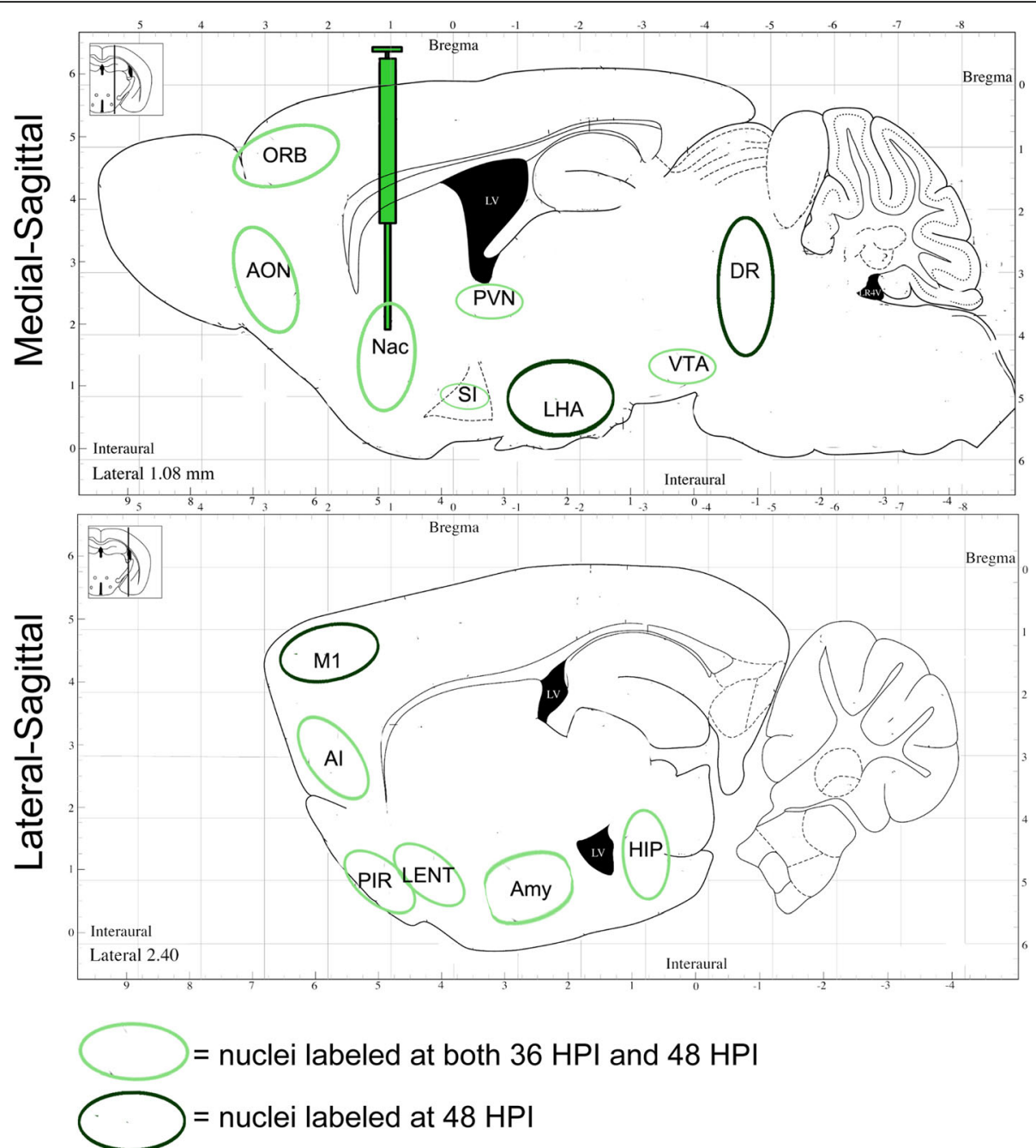

Fig. 6 The structural neural networks labeled by H8 in the NAc output pathway. Medial-sagittal and lateral-sagittal plates and labeled structures are from the Franklin and Paxinos Atlas (Franklin and Paxinos, 2001). Light green circles mark GFP-labeled structures by H8 tracer at both 36 hpi and $48 \mathrm{hpi}$; dark green circles mark GFP-labeled structures at $48 \mathrm{hpi}$

antibodies to clearly visualize labeling signals. To address the problem of low sensitivity, several different approaches have been used to enhance fluorescent protein expression in H129 tracers, including using strong promoters, expression regulators, or the insertion of several copies of fluorescent protein-encoding genes into the viral genome. However, these methods only add a limited number of copies of the transgene because HSV genomes undergo homologous recombination of repeated gene sequences. Thus, the transgene copy number is limited by HSV itself, restricting fluorescent protein expression.

Here, we designed and applied a Trojan horse-like strategy in order to construct a chimeric HSV/AAV vector to overcome the limitation of low fluorescent protein expression of H129-based vectors. We developed a chimeric virus, named H8, with high levels of fluorescent protein expression both in vitro and in vivo. The strategy was based on two important premises. First, AAV genomes have a simple and efficient replication system that requires the assistance of a helper virus (adenovirus or HSV) to replicate and package progeny viruses. Wildtype AAV genomes consists of only two genes: rep and cap. The rep gene encodes four nonstructural Rep proteins involved in the AAV viral life cycle, which mediates the amplification of the ITR-flanked genome. The cap gene encodes three structural proteins, VP1, VP2, and VP3, which form the icosahedral capsid [21]. The minimum requirement for AAV DNA replication and packaging is the ITRs, which flank the AAV genome. Second, HSV is a natural helper virus for AAV packaging. rAAV production relies entirely on the endogenous functions of the AAV Rep and Cap proteins and on the functions of the helper virus. HSV replication-associated proteins 
can be directly used by AAV for its efficient replication and packaging. The required HSV genes for AAV production include UL5, UL8, UL9, UL29, UL30, UL42, and UL52, all of which are components of the HSV core replication system $[35,36]$.

The Trojan horse-like strategy used in the current study is shown in Fig. 1a. The genomes of the HSV chimeric viruses enter the nucleus following infection of cells. With the assistance of HSV, the Rep replicase specifically recognizes ITR cis-elements and replicates the exogenous gene cassette flanked by ITRs, resulting in amplification of the copy numbers of the GOI (gene of interest). It can be seen that there are two sources of synergistic accumulation of exogenous gene transcription templates: 1) GOI genes carried by the HSV genome will be amplified with viral genomes replication (Fig.1a(1); 2) GOI genes specifically amplified by the AAV replication system, assisted by HSV helper proteins (Fig.1a(2), resulting in significant amplification of the number of GOI templates and enhancing protein expression. The $\mathrm{H} 8$ virus effectively expressed the AAV Rep protein, and its replication was only slightly slower than that of wildtype HSV, which indicated that Trojan horse-like construction strategy did not affect the replication phenotype of $\mathrm{H} 8$ virus. As expected, the green fluorescence of the $\mathrm{H} 8$ chimeric virus-infected cells was significantly brighter than that of H1-infected cells. qPCR analysis showed that the egfp/viral genome ratio for $\mathrm{H} 8$ was significantly higher than that of $\mathrm{H} 1$ in both in vitro and in vivo validation experiments (Fig. $1 \mathrm{f}$ and Fig. 2b), indicating that the Rep protein expressed by the chimeric vector effectively replicated and amplified the GOI. Similarly, Western blotting showed significantly increased EGFP expression by $\mathrm{H} 8$ virus compared with $\mathrm{H} 1$.

Previous studies have constructed HSV/AAV chimeric vectors to produce rAAV viruses by HSV-assisted packaging platform or to construct the core plasmids of chimeric HSV amplicon vectors [37, 38]. The difference was that there were some variations in the methods used to construct the chimeric vectors. HSV/AAV amplicon vectors are constructed by combining critical elements from HSV and AAV vectors, which contain only 2 short nucleotide sequences of HSV genome (HSV origin of replication (oriS) and HSV DNA cleavage/packaging sequence $(p a c)$ ) and inserting an AAV replication system into the amplicon plasmid backbone, which is then used as a gene delivery tool. The resulting packaged amplicon vectors are structurally HSV-like pseudoviral particles, the genomes of which contain no HSV-1 functional genes. Another application is using hybrid HSV/AAV viruses as a platform for rAAV manufacturing. Unlike the method described in the current study, the production of rAAV particles requires the insertion of the AAV rep and cap genes together into the HSV genome. However, to enhance transgene expression in this study, only rep and cis-acting ITR elements need to be inserted into the HSV genome, meaning that AAV particles will not be produced. Here, for the first time, we integrated an AAV replication system directly into the HSV viral genome for the purpose of replicating and amplifying exogenous genes carried by the HSV vector to achieve high-level protein expression. Both in vitro and in vivo experiments demonstrated that the exogenous gene was replicated and amplified, and that there was a significant increase in the expression of the exogenous protein. Furthermore, H8 chimeric viruses possessed the same anterograde transport phenotype as wild-type H129 (Fig. 3 and Additional file 1: Figure S1A), which indicated that the HSV/ AAV chimaera construction strategy did not change the infection and anterograde spreading characteristics of $\mathrm{H} 8$, and $\mathrm{H} 8$ could also be used as an anterograde tracer. Thus, the H8 strain could be more convenient than currently available anterograde tracing tools because it does not require additional immunohistochemical amplification of the fluorescent signal.

C57BL/6 mice infected with $\mathrm{H} 8$ showed high levels of EGFP expression at $36 \mathrm{~h}$ post-infection, although fewer brain regions were labeled at this point than at $48 \mathrm{~h}$ post-infection. However, even at the earlier time point, fluorescence in the labeled regions was sufficiently bright to image. Therefore, the $\mathrm{H} 8$ virus provides us with a simpler method to perform time course labeling to dissect neural circuits. Interestingly, the behavior change of mice infected with $\mathrm{H} 8$ was milder compared with mice injected with $\mathrm{H} 1$ (data not shown). This may be because $\mathrm{H} 8$ replicated more slowly than $\mathrm{H} 1$ and induced a less powerful inflammatory response. In addition to the merits of the novel $\mathrm{H} 8$ virus, there are still some limitations. We recently found that H129-based viral tracers exhibited the phenotype of axon terminal uptake, which led to unintended retrograde labeling of non-specific upstream innervating neurons [31]. H8 may also have the same potential problem, because the Trojan horse-like enhancement strategy described in this study does not change the infection tropism and preference of the H129 virus. On this basis, more research is needed to develop more rigorous HSV anterograde tracing tools.

In summary, we generated a novel HSV anterograde neural circuit tracer, H8, using the Trojan horse-like enhancement strategy. $\mathrm{H} 8$ could be used as an anterograde trans-multisynaptic tracer for fast and effective tracing without additional immunostaining. Meanwhile, it was important to caution that $\mathrm{H} 8$ might exhibit some nonspecific retrograde labeling at longer post-inoculation intervals. To avoid the non-specific tracing, the sampling time should be limited to 3 days or a shorter time postinfection. In addition to being developed as a tracing tool, HSV-based vectors carrying exogenous genes have long been explored for gene therapy applications [39-41]. The 
unique features of HSV make it particularly attractive for use in transgene delivery to the central nervous system. The Trojan horse-like strategy described here may be applied as a general enhanced expression strategy for HSVbased viral tracers and gene delivery vectors.

\section{Supplementary information}

Supplementary information accompanies this paper at https://doi.org/10. 1186/s13041-020-0544-2.

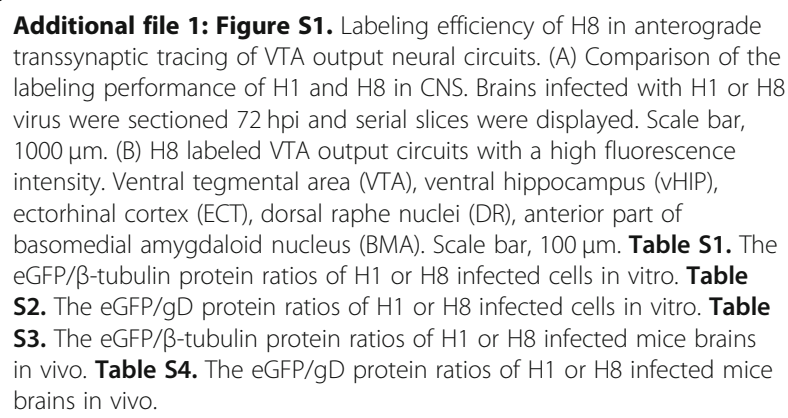

\section{Abbreviations}

AAV: Adeno-associated virus; Al: Agranular insular cortex; Amy: Amygdala; AON: Anterior olfactory nucleus; BMA: Anterior part of basomedial amygdaloid nucleus; DMEM: Dulbecco's minimum essential media; DR: Dorsal raphe nuclei; DRN: Dorsal raphe nuclei; ECT: Ectorhinal cortex; EGFP: Enhanced green fluorescent protein; ENT: Entorhinal cortex; GOl: Gene of interest; HIP: Hippocampus; HPI: Hours post infection; HSV: Herpes simplex virus; ITR: Inverted terminal repeat; LHA: Lateral hypothalamus; NAc: Accumbens nucleus; ORB: Orbital cortex; Pir: Piriform cortex; PRV: Pseudorabies virus; PVN: Paraventricular thalamic nucleus; rAAV: Recombinant AAV; SI: Substantia innominate; V1: Primary visual cortex; VHIP: Ventral hippocampus; VTA: Ventral tegmental area

\section{Acknowledgements}

The authors would like to express their gratitude to Professor Lynn Enquist (Princeton University, Princeton, NJ) for generously providing the H129 viral strain, and Feilong Yu from College of Life Sciences, Wuhan University for helping to conduct the western blot experiment, and Miss Pingping An and Yanqiu Li from Wuhan Institute of Physics and Mathematics for keeping the mice.

\section{Authors' contributions}

HW, PS and FX developed the idea, PS, HW, MY, JX, ZH, SJ and YL performed the experiments, PS, HW, MY, SJ and FX analyzed the data, PS, HW and FX conceived the manuscript and wrote the text, and PS, HW generated the figures. All authors read and approved the final manuscript.

\section{Funding}

The work was supported by National Natural Science Foundation of China (31771198, 31400976, 91632303 and 91732304), Chinese Ministry of Science and Technology (2015CB755601), The Strategic Priority Research Program of Chinese Academy of Sciences (XDB32030200), Science and Technology Planning Project of Guangdong Province (2018B030331001) and Key Laboratory of Magnetic Resonance in Biological Systems, Chinese Academy of Sciences (Y7L0021001).

\section{Availability of data and materials}

The datasets used or analysed during the current study are available from the corresponding author on reasonable request.

\section{Ethics approval and consent to participate}

All experimental and surgical procedures were conducted in accordance with the guidelines of the Animal Care and Use Committees at the Wuhan Institute of Physics and Mathematics, Chinese Academy of Sciences. All the experiments with viruses were performed in bio-safety level 2 (BSL-2) laboratory and animal facilities. Consent to participate is not applicable.

\section{Consent for publication}

Consent for publication is not applicable.

\section{Competing interests}

The authors declare that they have no competing interests.

\section{Author details}

${ }^{1}$ Wuhan National Laboratory for Optoelectronics, Huazhong University of Science and Technology, Wuhan 430074, China. ${ }^{2}$ Center for Brain Science, State Key Laboratory of Magnetic Resonance and Atomic and Molecular Physics, Key Laboratory of Magnetic Resonance in Biological Systems, Wuhan Center for Magnetic Resonance, Wuhan Institute of Physics and Mathematics, Innovation Academy for Precision Measurement Science and Technology, Chinese Academy of Sciences, Wuhan 430071, China. ${ }^{3}$ University of Chinese Academy of Sciences, Beijing 100049, China. ${ }^{4}$ Huazhong University of Science and Technology (HUST)-Suzhou Institute for Brainsmatics, JITRI Institute for Brainsmatics, Suzhou 215125, China. ${ }^{5}$ Shenzhen Key Lab of Neuropsychiatric Modulation, Guangdong Provincial Key Laboratory of Brain Connectome and Behavior, CAS Key Laboratory of Brain Connectome and Manipulation, The Brain Cognition and Brain Disease Institute (BCBDI), Shenzhen Institutes of Advanced Technology, Chinese Academy of Sciences; Shenzhen-Hong Kong Institute of Brain Science-Shenzhen Fundamental Research Institutions, Shenzhen 518055, China. ${ }^{6}$ Center for Excellence in Brain Science and Intelligence Technology, Chinese Academy of Sciences, Shanghai 200031, China.

Received: 17 August 2019 Accepted: 5 January 2020

Published online: 13 January 2020

\section{References}

1. Card JP, Enquist LW. Transneuronal circuit analysis with pseudorabies viruses. In: Current protocols in neuroscience; 2001. Chapter 1:Unit1 5.

2. Callaway EM. Transneuronal circuit tracing with neurotropic viruses. Curr Opin Neurobiol. 2008;18(6):617-23.

3. Nassi JJ, Cepko CL, Born RT, Beier KT. Neuroanatomy goes viral! Front Neuroanat. 2015;9:80.

4. Li J, Liu T, Dong Y, Kondoh K, Lu Z. Trans-synaptic neural circuit-tracing with neurotropic viruses. Neurosci Bull. 2019;35(5):909-20.

5. Jeff DeFalco MT, Enquist L, Friedman JM. Virus-assisted mapping of neural inputs to a feeding Center in the Hypothalamus. Science. 2001;291:2608.

6. Wickersham IR, Finke S, Conzelmann KK, Callaway EM. Retrograde neuronal tracing with a deletion-mutant rabies virus. Nat Methods. 2007:4(1):47-9.

7. Wickersham IR, Lyon DC, Barnard RJ, Mori T, Finke S, Conzelmann KK, et al. Monosynaptic restriction of transsynaptic tracing from single, genetically targeted neurons. Neuron. 2007;53(5):639-47.

8. Kramer T, Enquist LW. Directional spread of Alphaherpesviruses in the nervous system. Viruses-Basel. 2013;5(2):678-707.

9. Dix RD, Mckendall RR, Baringer JR. Comparative Neurovirulence of herpessimplex virus Type-1 strains after peripheral or intracerebral inoculation of Balb/C mice. Infect Immun. 1983;40(1):103-12.

10. Boldogkoi Z, Sik A, Denes A, Reichart A, Toldi J, Gerendai I, et al. Nove tracing paradigms--genetically engineered herpesviruses as tools for mapping functional circuits within the CNS: present status and future prospects. Prog Neurobiol. 2004;72(6):417-45.

11. Beier KT, Saunders A, Oldenburg IA. Anterograde or retrograde transsynaptic labeling of CNS neurons with vesicular stomatitis virus vectors. PNAS. 2011; 108(37):15414-9.

12. Mark C, Zemanick PLS, Dix RD. Direction of transneuronal transport of herpes simplex virus 1 in the primate motor system is strain-dependent. Proc Natd Acad Sci. 1991:88:8048-51.

13. Lo L, Anderson DJ. A Cre-dependent, anterograde transsynaptic viral tracer for mapping output pathways of genetically marked neurons. Neuron. 2011; 72(6):938-50.

14. Wojaczynski GJ, Engel EA, Steren KE, Enquist LW, Patrick Card J. The neuroinvasive profiles of $\mathrm{H} 129$ (herpes simplex virus type 1) recombinants with putative anterograde-only transneuronal spread properties. Brain Struct Funct. 2015;220(3):1395-420. 
15. Edward M, Barnett GDE, Suq N, Perlman S, Cassew MD. Anterograde tracing of trigeminal afferent pathways from the murine tooth pulp to cortex using herpes simplex virus type 1. J Neurosci. 1995;15(4):2972-84.

16. Rinaman L, Schwartz G. Anterograde transneuronal viral tracing of central viscerosensory pathways in rats. J Neurosci. 2004;24(11):2782-6.

17. Song CK, Schwartz GJ, Bartness TJ. Anterograde transneuronal viral tract tracing reveals central sensory circuits from white adipose tissue. Am J Physiol Regul Integr Comp Physiol. 2009;296(3):R501-11.

18. Salganik M, Hirsch ML, Samulski RJ. Adeno-associated virus as a mammalian DNA vector. Microbiol Spectr. 2015;3(4). https://doi.org/10.1128/ microbiolspec.MDNA3-0052-2014.

19. Naso MF, Tomkowicz B, Perry WL, Strohl WR. Adeno-associated virus (AAV) as a vector for gene therapy. Biodrugs. 2017;31(4):317-34

20. Kay MA, Nakai H. Looking into the safety of AAV vectors. Nature. 2003; 424(6946):251.

21. Aponte-Ubillus JJ, Barajas D, Peltier J, Bardliving C, Shamlou P, Gold D. Molecular design for recombinant adeno-associated virus (rAAV) vector production. Appl Microbiol Biotechnol. 2018;102(3):1045-54.

22. Geoffroy MC, Salvetti A. Helper functions required for wild type and recombinant adeno-associated virus growth. Curr Gene Ther. 2005;5(3):26571.

23. Buller RM, Janik JE, Sebring ED, Rose JA. Herpes simplex virus types 1 and 2 completely help adenovirus-associated virus replication. J Virol. 1981;40(1): 241-7.

24. Clement N, Knop DR, Byrne BJ. Large-scale adeno-associated viral vector production using a herpesvirus-based system enables manufacturing for clinical studies. Hum Gene Ther. 2009;20(8):796-806.

25. Fraefel C, Marconi P, Epstein AL. Herpes simplex virus type 1 (HSV-1)-derived amplicon vectors for gene transfer and gene therapy. Methods Mol Biol. 2015;1254:295-316.

26. Saydam O, Glauser DL, Fraefel C. Construction and packaging of herpes simplex virus/adeno-associated virus (HSV/AAV) hybrid amplicon vectors. Cold Spring Harb Protoc. 2012;2012(3):352-6.

27. Costantini LC, Jacoby DR, Wang S, Fraefel C, Breakefield XO, Isacson O. Gene transfer to the nigrostriatal system by hybrid herpes simplex virus/adenoassociated virus amplicon vectors. Hum Gene Ther. 1999;10(15):2481-94.

28. de Oliveira AP, Fraefel C. Herpes simplex virus type 1/adeno-associated virus hybrid vectors. Open Virol J. 2010;4:109-22.

29. Johnston KM, Jacoby D, Pechan PA, Fraefel C, Borghesani P, Schuback D, et al. HSV/AAV hybrid amplicon vectors extend transgene expression in human glioma cells. Hum Gene Ther. 1997;8(3):359-70.

30. Yang H, Yang J, Xi W, Hao S, Luo B, He X, et al. Laterodorsal tegmentum interneuron subtypes oppositely regulate olfactory cue-induced innate fear. Nat Neurosci. 2016;19(2):283-9.

31. Su P, Wang HD, Xia JJ, Zhong X, Hu L, Li YL, et al. Evaluation of retrograde labeling profiles of HSV1 H129 anterograde tracer. J Chem Neuroanat. 2019; 100:101662.

32. Simmons PA, Lemmon $\mathrm{V}$, Pearlman AL. Afferent and efferent connections of the striate and Extrastriate visual-cortex of the Normal and Reeler mouse. J Comp Neurol. 1982;211(3):295-308.

33. Zingg B, Hintiryan H, Gou L, Song MY, Bay M, Bienkowski MS, et al. Neural networks of the mouse neocortex. Cell. 2014;156(5):1096-111.

34. Soares-Cunha C, Coimbra B, Sousa N, Rodrigues AJ. Reappraising striatal D1 and D2-neurons in reward and aversion. Neurosci Biobehav Rev. 2016;68: 370-86.

35. Alazard-Dany N, Nicolas A, Ploquin A, Strasser R, Greco A, Epstein AL, et al. Definition of herpes simplex virus type 1 helper activities for adenoassociated virus early replication events. PLoS Pathog. 2009;5(3):e1000340.

36. Stutika C, Huser D, Weger S, Rutz N, Hessler M, Heilbronn R. Definition of herpes simplex virus helper functions for the replication of adenoassociated virus type 5. J Gen Virol. 2015;96(Pt 4):840-50.

37. Oehmig A, Fraefel C, Breakefield XO, Ackermann M. Herpes simplex virus type 1 amplicons and their hybrid virus partners, EBV, AAV, and retrovirus. Curr Gene Ther. 2004;4(4):385-408.

38. Booth MJ, Mistry A, Li X, Thrasher A, Coffin RS. Transfection-free and scalable recombinant AAV vector production using HSV/AAV hybrids. Gene Ther. 2004;11(10):829-37.

39. Marconi P, Fraefel C, Epstein AL. Herpes simplex virus type 1 (HSV-1)-derived recombinant vectors for gene transfer and gene therapy. Methods Mol Biol. 2015;1254:269-93.
40. Goins WF, Huang S, Cohen JB, Glorioso JC. Engineering HSV-1 vectors for gene therapy. Methods Mol Biol. 2014;1144:63-79.

41. Maguire-Zeiss KA, Bowers WJ, Federoff HJ. HSV vector-mediated gene delivery to the central nervous system. Curr Opin Mol Ther. 2001;3(5):48290.

\section{Publisher's Note}

Springer Nature remains neutral with regard to jurisdictional claims in published maps and institutional affiliations.
Ready to submit your research? Choose BMC and benefit from:

- fast, convenient online submission

- thorough peer review by experienced researchers in your field

- rapid publication on acceptance

- support for research data, including large and complex data types

- gold Open Access which fosters wider collaboration and increased citations

- maximum visibility for your research: over $100 \mathrm{M}$ website views per year

At BMC, research is always in progress.

Learn more biomedcentral.com/submissions 